\title{
INVESTIGATIONS IN THE SPECTRAL REGION BETWEEN 20 AND $40 \mu$
}

\author{
By John Strong* \\ California Institute of Technology, Pasadena
}

(Received May 5, 1931)

\begin{abstract}
An apparatus is described which is convenient for studying the optical properties of substances with reststrahlen having wave-lengths from 6 to $150 \mu$. A vibrationless support is described, the essential features of which are copied from the design of $R$. Müller but the construction is simplified. The transmission of several gases was studied with reststrahlen having wave-lengths 20 to $33 \mu$. $\mathrm{SO}_{2}$ shows strong absorption at $20.75 \mu$. The reflectivity of $\mathrm{SO}_{2}$ was tested and found to be zero at both $20.75 \mu$ and $8.7 \mu$ where it has strong absorption bands. Gas absorptions from 20 to $33 \mu$ are compared with the Raman indications. Transmissivities and reflectivities of various materials are given for the spectral region 20 to $33 \mu . \beta-\mathrm{MgO}$ was found to have a reststrahlen near $23 \mu$. Potassium iodide was found to be transparent to wave-lengths greater than $33 \mu$.
\end{abstract}

THE region of the spectrum between 20 and $40 \mu$ has not been as extensively investigated as the regions on either side, due to the lack of materials having suitable optical properties for windows, dispersing prisms and filters. The use of various reststrahlen and gratings with open thermocouples (or microradiometers) has given us most of the knowledge we have of the optical properties of substances in this region. Recently, L. Kellner ${ }^{1}$ has studied the transmission of paraffin (Kahlbaum M.P. $68^{\circ}-72^{\circ} \mathrm{C}$ ) and found that layers of $1.2 \mathrm{~mm}$ thickness are sufficiently transparent beyond $20 \mu$ for use as thermocouple windows. This discovery materially decreases the difficulty of investigation in this region.

Potassium chloride is transparent to $23 \mu$, potassium bromide to $30 \mu$, and potassium iodide to wave-lengths greater than $33 \mu$. The technique for growing large crystals of these materials was developed by the author ${ }^{2}$ at the University of Michigan. With these materials available the region now open for prism spectroscopy extends beyond $15 \mu$ by more than an octave of frequencies. The purpose of this present paper is the extension of our knowledge of the optical properties of substances in this new region.

Schaefer and Matossi $i^{3}$ have prepared a table of the reststrahlen bands which have well established wave-lengths. Several of these bands fall in the spectral region $20-40 \mu$ and the present investigation was made with these bands.

The reststrahlen bands are not as monochromatic as might be desired but this is compensated for by the abundance of available energy and the

* National Research Fellow.

${ }^{1}$ L. Kellner, geb. Sperling, Zeits. f. Physik 56, 215 (1929).

2 John Strong, Phys. Rev. 36, 1663 (1930).

${ }^{3}$ Schaefer and Matossi, Das Ultrarote Spektrum, p. 60 (1930). 
wide range of wave-lengths which are obtainable with the one technique. Wave-lengths from 6 to $150 \mu$ are thus obtainable, corresponding to a frequency range of more than five octaves.

\section{The Apparatus}

A reststrahlen apparatus was devised for these experiments which was superior to older reststrahlen arrangements in the following ways. First, the crystal reflectors needed were of small size and, consequently, easier to obtain than the large crystals required for the old arrangements. Second, the transfer of crystals in going from one wave-length to another was a simple operation requiring only a few seconds of time and this operation did not disturb the air through which the radiations passed and thus it was possible to keep the air dry at all times.

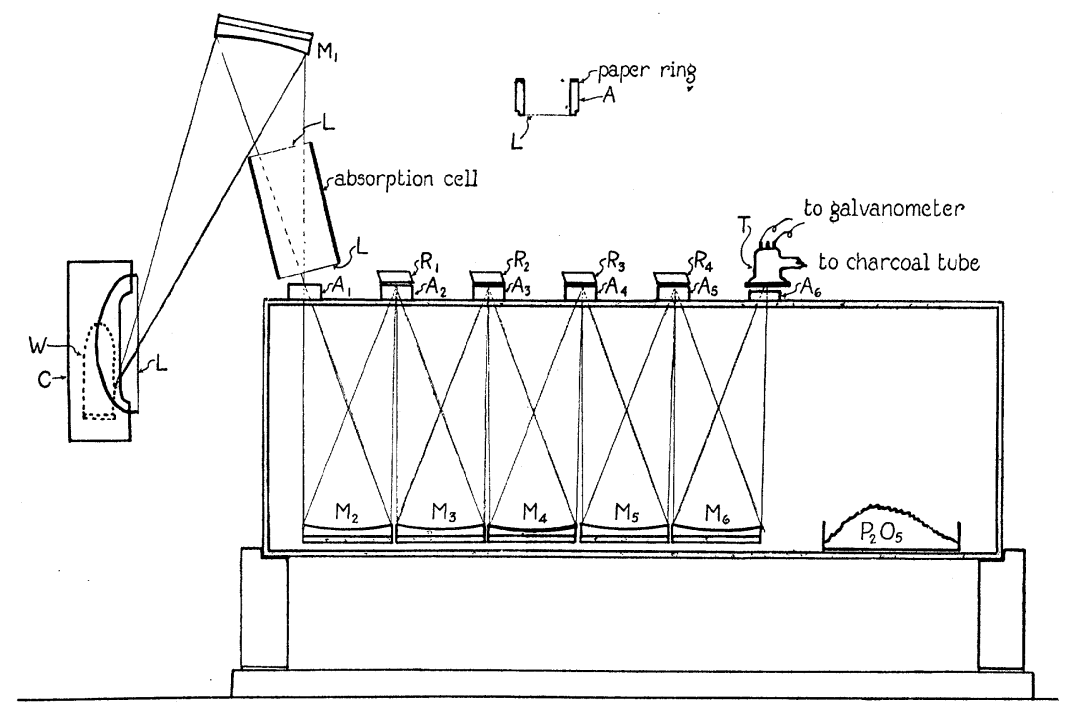

Fig. 1. Diagram of reststrahlen apparatus.

Fig. 1 is a diagram of the reststrahlen apparatus used for this research. Light from the Welschback mantle is reflected by the mirror, $M_{1}$, into the reststrahlen apparatus through the circular hole, $A_{1}$, where it subsequently passes, after reflection from the concave spherical mirror, $M_{2}$, to a second circular hole, $A_{2}$. A crystal mirror, $R_{1}$, covers this hole and reflects the light to the concave mirror, $M_{3}$, where it is returned for the second reststrahlen mirror, $R_{2}$. After three (or four) successive reflections from reststrahlen mirrors and possibly one reflection from a metal mirror, the light is focused onto the receivers of the vacuum thermocouple, $T$. The thermocouple is a compensated two junction type, with one of the junctions covered by a rocksalt plate. This thermocouple was made for me by Dr. C. H. Cartwright. The window for the thermocouple was a $1 \mathrm{~mm}$ plate of potassium iodide.

For studying the absorption of gases, an absorption cell may be introduced in to the radiation path between the mirror, $M_{1}$, and the circular hole, $A_{1}$. 
The housing for the reststrahlen apparatus is made from brass sheet laid over a framework of half inch square iron rod. This is mounted on a wooden support. The corners were sealed with beeswax to make the apparatus gas tight so the air might be dried with $\mathrm{P}_{2} \mathrm{O}_{5}$. The base of the housing was penetrated by three adjusting screws (not shown) for each of the spherical mirrors, $M_{2}$ to $M_{6}$. The outside of the housing was covered with a layer of felt and to protect further the apparatus from temperature fluctuation, it was encased within galvanized iron walls. The insert, $A$, in Fig. 1 shows a cross section of one of the small brass cylinders which fit over the holes $A_{1}$ to $A_{5}$. This is drawn to a scale twice as large as that for the rest of the figure. The cylinders each have a lacquer window, $L$, stretched over their base.

These lacquer windows are very transparent (96 to 100 percent) for waves longer than $20 \mu$ and permit the air within the apparatus to be kept dry, when the reststrahlen mirrors are being interchanged. A paper ring on the top of each cylinder protects the mirrors from being scratched.

Because the silver mirrors are not used on their optical axes, there is considerable astigmatism. This results in a large final image with smaller intensity than if there were no astigmatism. The illumination in the center of the final image will increase, however, as the size of the reststrahlen mirrors is increased. It is believed that since the reststrahlen surfaces used were each $\frac{3}{4}$ inches in diameter, the illumination of the thermocouple receivers was not greatly attenuated due to astigmatism.

In order to have the galvanometer free from microseismic vibrations, it was mounted on a vibrationless support. This support was a simplification of the one designed by R. Müller, ${ }^{4}$ and was constructed in the following manner. Three triangular plywood boards, each $\frac{1}{2}$ " thick and $11^{\prime \prime}$ on an edge were clamped and bored with six $\frac{3}{8}$ " holes, two holes in each corner. (See Fig. 2). The two upper triangles were separated $20^{\prime \prime}$ and bolted together at this distance with three $\frac{3}{8}$ " brass rods, one at each corner, to form the swinging framework for the galvanometer. The top and bottom plywood triangles were fastened together by three $24^{\prime \prime}$ brass rods $3 / 32$ " diameter. These rods passed freely through the remaining $\frac{3}{8}$ " holes in the middle triangle. The bottom triangle served for the base of the support while the $3 / 32$ " rods afforded the necessary looseness of mechanical connection between the swinging framework and the earth. Three levelling nuts screw on the termini of the $3 / 32$ " rods below the bottom triangle. Four $10^{\prime \prime}$ pie pans are filled with transformer oil and stacked on top of the swinging framework to dampen oscillations. These pans were filled to the depth found by experiment to give maximum damping. The galvanometer was mounted on the middle triangle and above it on a tripod ballast was placed to make the period of oscillation of the support about two seconds. When this period is attained, the mechanical coupling is sufficiently loose to isolate effectively, the galvanometer from the horizontal components of microseismic vibrations. No protection against vertical components is necessary as these do not cause a spurious deflection

${ }^{4}$ R. Müller, Ann. d. Physik 1, 613 (1929). 
of the galvanometer. In order to clamp rigidly the support for making adjustments, tapered pins are dropped along the side of the $3 / 32$ " rods in two of the holes in the middle plate. The swinging framework suffers a slight parallel displacement when these pins are removed but this does not affect the galvanometer adjustment. This support is conveniently housed on a corner shelf to shield it from air currents.

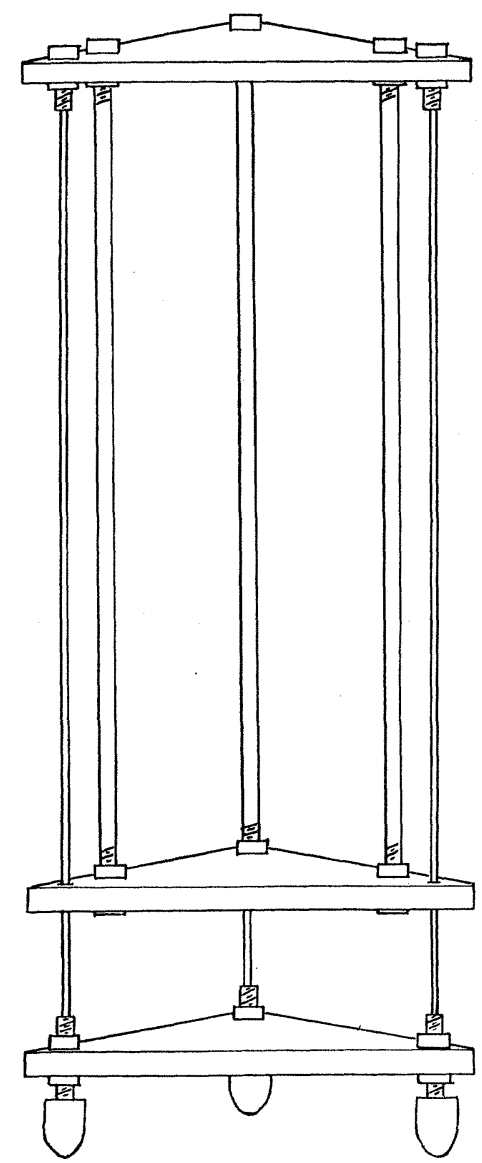

Fig. 2. Vibrationless support for galvanometer.

In order to shield the Welschback mantle, $W$, from air currents, a lacquer film, $L$, was stretched across the opening of the water-cooled chamber, $C$, which surrounds it. The radiations were taken off at nearly grazing incidence because the mantle was porous. Although the mantle material is quite opaque to waves $20-40 \mu$, the mantle at normal incidence, showed an absorption of only 70 percent for these radiations due to its porosity.

The thermocouple receivers were blackened with a paint made from pulverized mantle material and colorless lacquer. Tests showed that these re- 
ceivers absorbed as much as when coated with a mixture of soot and water glass but the paint did not cause the receivers to curl as water glass did.

\section{The Reststrahlen}

The table of Schaefer and Matossi is reproduced in part. This gives the method used for obtaining reststrahlen having wave-lengths of 20 to $33 \mu$.

TABLE I.

\begin{tabular}{lccrrl}
\hline \hline Substance & $\begin{array}{l}\text { Number of } \\
\text { reflections }\end{array}$ & Filter & $\lambda$ & $E$ & \multicolumn{1}{c}{ Literature } \\
\hline Quartz & 4 & $2.5 \mathrm{~mm} \mathrm{AgCl}$ & $\begin{array}{r}20.75 \mu \\
8.7 \mu\end{array}$ & $\begin{array}{r}18.0 \\
12.0\end{array}$ & $\begin{array}{l}\text { H. Rubens and E. F. Nichols, } \\
\text { Wied. Ann. 60, 418 (1897). }\end{array}$ \\
Fluorite & 3 & $5 \mathrm{~mm} \mathrm{KCl}$ & $22.9 \mu$ & 6.0 & $\begin{array}{l}\text { H. Rubens Berl. Ber., 1915, p.4. } \\
\text { Calcite }\end{array}$ \\
$\begin{array}{l}\text { Fluorite } \\
\text { Marble }\end{array}$ & 2 & $3 \mathrm{~mm} \mathrm{KBr}$ & $27.3 \mu$ & 8.0 & $\begin{array}{l}\text { H. Liebisch and H. Rubens, Berl. } \\
\text { Ber., 1919, p. 876. }\end{array}$ \\
Fluorite & 4 & & $\begin{array}{r}29.4 \mu \\
6.7 \mu\end{array}$ & $\begin{array}{r}14.0 \\
4.0\end{array}$ & $\begin{array}{l}\text { E. Aschkinass, Ann. d. Physik } \\
1,42,(1900) .\end{array}$ \\
& $1.2 \mathrm{~mm} \mathrm{KBr}$ & $32.8 \mu$ & 0.75 & $\begin{array}{l}\text { H. Rubens, Wied. Ann. 69, 576 } \\
(1899) .\end{array}$ \\
\hline \hline
\end{tabular}

The numbers given in column $E$ represent the observed galvanometer deflection in centimeters for the various reststrahlen. A Leeds and Northrup high sensitivity galvanometer was used with the scale at 3 meters. In order to eliminate shorter waves as much as possible a soot filter was used and these values are for the energy transmitted by this filter.

In the present experiments a $1 \mathrm{~cm} \mathrm{KCl}$ filter was substituted for the 2.5 $\mathrm{mm} \mathrm{AgCl}$ filter recommended by Rubens and Nichols. This is justified by the transmission curves given by Rubens and Trowbridge ${ }^{5}$ for $\mathrm{AgCl}$ and $\mathrm{KCl}$.

In the present experiments, the $27.3 \mu$ rays were not polarized as specified by Liebisch and Rubens and it was not possible to test the wave-length of the rays to find the effect of this omission.

The $32.8 \mu$ rays were apparently homogeneous for the transmission of a $\mathrm{KBr}$ plate. $1.2 \mathrm{~mm}$ thickness was found to be 68 percent while Rubens states that it transmits more than $\frac{2}{3}$ of the $32.8 \mu$ reststrahlen.

Except for the $20.75 \mu$ and $29.4 \mu$ reststrahlen a rocksalt shutter of $3 \mathrm{~mm}$ thickness was used. For these reststrahlen both rocksalt and metal shutters were used. If $E_{T}$ was the energy of both reststrahlen and $A_{T}$ was the absorption of the sample for this energy, then if $E_{s}$ was the energy passed by a rocksalt filter, i.e., the energy of the short reststrahlen, and $A_{s}$ the part of this energy absorbed by the sample, then, allowing $9 / 10$ as the transmission of the rocksalt shutter for the short waves, the long wave (i.e. the 20.75 and $29.4 \mu$ reststrahlen) energy is $\left(E_{T}-E_{s} / 0.9\right)$ and the long wave energy absorbed by the sample is $\left(A_{T}-A_{s} / 0.9\right)$.

${ }^{5}$ H. Rubens and A. Trowbridge, Wied. Ann. 60, 724 (1897). 


\section{Measurements}

Gases. The gases used for the present measurements were not especially purified. They were drawn from stock cylinders or were the vapors of chemically pure liquids. The chief difficulty in obtaining consistent results was due to the variable concentration of vapor within the absorption cell. Benzene and $\mathrm{CCl}_{4}$ were observed to wet the lacquer windows at times and this gives an indication that these liquids would, in all probability, be transparent. The values given in Table II are averages of four to eight independent runs taken on different days and are thought to be correct to about 2 percent. They are slightly different from some preliminary results published in a Letter to the Editor. These differences in some cases are due to additional data but for the wave-lengths 20.75 and $29.4 \mu$ the differences are due chiefly to corrections for the transmissivity of the rocksalt filter used.

TABLE II. Percent transmission. (Length of cell, 4 inches).

\begin{tabular}{lcrrrrrrr}
\hline \hline \multicolumn{1}{c}{ Material } & $\begin{array}{c}\text { Pressure } \\
\text { Millimeters }\end{array}$ & $6.7 \mu$ & $8.7 \mu$ & $20.75 \mu$ & $22.9 \mu$ & $27.3 \mu$ & $29.4 \mu$ & $32.8 \mu$ \\
\hline $\mathrm{NH}_{3}$ & 760 & 24 & 26 & 79 & 93 & 83 & 82 & 62 \\
$\mathrm{~N}_{2} \mathrm{O}$ & 760 & 102 & 77 & 90 & 100 & 101 & 101 & 102 \\
$\mathrm{C}_{2} \mathrm{H}_{2}$ & 760 & 95 & 92 & 99 & 101 & 101 & 100 & 98 \\
$\mathrm{H}_{2} \mathrm{~S}$ & 760 & 97 & 98 & 98 & 97 & 92 & 90 & 83 \\
$\mathrm{SO}_{2}$ & 760 & 98 & 5 & 7 & 58 & 100 & 100 & 96 \\
$\mathrm{C}_{6} \mathrm{H}_{6}$ & 96 & 65 & 97 & 102 & 99 & 100 & 98 & 95 \\
$\mathrm{CCl}_{4}$ & 114 & 95 & 99 & 97 & 99 & 99 & 99 & 91 \\
$\mathrm{CS}_{2}$ & 361 & 30 & 98 & 100 & 86 & 98 & 99 & 96 \\
$\mathrm{CHCl}_{3}$ & 200 & 93 & 90 & 99 & 98 & 98 & 97 & 97 \\
$\left(\mathrm{C}_{2} \mathrm{H}_{5}\right)_{2} \mathrm{O}$ & 526 & 17 & 6 & 61 & 45 & 69 & 71 & 61 \\
\hline \hline
\end{tabular}

The gradual decrease of transparency for $\mathrm{H}_{2} \mathrm{~S}$ and $\mathrm{N}_{3} \mathrm{H}$ at longer wavelengths may be due to the short wave-length end of the pure rotation spectrum.

The only strong absorption band discovered in the new spectral region was for $\mathrm{SO}_{2}$ at $20.75 \mu$. This band agrees with Raman indications ${ }^{6}$ and is possibly the third fundamental band for $\mathrm{SO}_{2}$. The strong absorption of $\mathrm{SO}_{2}$ for both the reststrahlen of quartz is quite striking. The absorption cell filler with $\mathrm{SO}_{2}$ cuts off these radiations almost the same as a metal shutter.

R. W. Wood ${ }^{7}$ has shown that the mercury line 2536 is reflected by hot mercury vapor at a high pressure. He states "It appeared highly probable that if the molecular resonators were packed closely enough together, the secondary wavelets which they emit, having a definite phase relation would unite into a single wave, and the scattered light would disappear, regular reflection taking its place." Because of the strong absorption of $\mathrm{SO}_{2}$ for the reststrahlen of quartz it was decided to test this hypothesis. High pressures should not be necessary on account of the long wave-lengths involved. Accordingly, a cell was fitted with a window of $\mathrm{KBr}$ and one of the quartz reststrahlen plates was replaced by it in such a way that there was reflection from the outer and inner surfaces of the window. The cell was connected to a vacuum pump and

${ }^{6}$ R. G. Dickinson and S. Stewart West, Phys. Rev. 35, 1126 (1930).

${ }^{7}$ R. W. Wood, Physical Optics, p. 429 (1929). 
a tank of $\mathrm{SO}_{2}$ by a three way stopcock so that it might be alternately evacuated and filled with $\mathrm{SO}_{2}$ at a pressure of two atmospheres. No change, whatever, in the galvanometer was observed when the cell was emptied and filled with $\mathrm{SO}_{2}$. This seems to show that this gas does not reflect at either $8.7 \mu$ or $20.75 \mu$.

The results of Table II are in agreement with results of Rubens and von Wartenberg 8 for the $22.9 \mu$ reststrahlen with the exception of $\mathrm{CS}_{2}$. For this gas, using a cell about 8 " long, these authors get a value of 97.8 percent as compared with my value of 86 percent for a 4 " cell.

Coblentz ${ }^{9}$ observes absorption bands at or near $6.7 \mu$ for liquid $\mathrm{CHCl}_{3}$ $(0.16 \mathrm{~mm}$ layer $)$ and $\mathrm{CCl}_{4}(0.1 \mathrm{~mm}$ layer $)$ which are not observed for the vapor with the $6.7 \mu$ reststrahlen.

For $\mathrm{CCl}_{4}$ there is a Raman line corresponding to an active infrared vibration at a wave-length of $31.6 \mu$ and for $\mathrm{CHCl}_{3}$ there is a line corresponding to $27.93 \mu$. Also for $\left(\mathrm{C}_{2} \mathrm{H}_{5}\right)_{2} \mathrm{O}$ there is a line corresponding to a wavelength at $23 \mu$. There is no corresponding absorption for the $\mathrm{CHCl}_{3}$ line but the low transmission of ether at $22.9 \mu$ and $\mathrm{CCl}_{4}$ at $32.8 \mu$ may be associated with the Raman indications.

Optical properties of various substances. Lacquer films may be prepared by dropping a single drop of colorless brushing lacquer on a large water surface. The lacquer spreads out immediately and the amyl acetate evaporates leaving a tenacious film. These films are useful as windows for absorption cells and so their optical properties are of interest. Since the films are of the order of $1 \mu$ thickness, there is no total reflection on account of the destructive interference between the energy reflected from the front and back surfaces. The absorption of a typical film is given in the first row of Table III. These films are so transparent that the reststrahlen are not seriously weakened in passing twice through four films, besides the sooted film over the first hole in the reststrahlen apparatus and the film over the Welschback mantle chimney. Values for a film covered with soot are also given in Table III.

TABLE III. Percent transmission.

\begin{tabular}{|c|c|c|c|c|c|c|c|c|}
\hline Material & Description & $6.7 \mu$ & $8.7 \mu$ & $20.75 \mu$ & $22.9 \mu$ & $27.3 \mu$ & $29.4 \mu$ & $32.8 \mu$ \\
\hline \multirow[t]{2}{*}{ Lacquer film } & $\begin{array}{l}\text { Thickness of order of } \\
\text { wave-length of visible }\end{array}$ & & & & & & & \\
\hline & light & 96 & 93 & 97 & 98 & 99 & 99 & 100 \\
\hline Mica & $10 \mu$ thickness & 83 & 22 & 19 & 00 & 35 & 42 & 44 \\
\hline \multirow{4}{*}{$\begin{array}{l}\text { Soot on } \\
\text { Lacquer film } \\
\text { Amorphus } \\
\text { quartz } \\
\text { Glass } \\
\text { Cellophane }\end{array}$} & Opaque to visible & 25 & 22 & 67 & 53 & 60 & 67 & 60 \\
\hline & $10 \mu$ thickness & 86 & 02 & 01 & 03 & 51 & 55 & 68 \\
\hline & $3 \mu$ thickness & 93 & $0 \overline{7}$ & 12 & 14 & 48 & 51 & 56 \\
\hline & $\begin{array}{l}25 \mu \text { thickness Ciga- } \\
\text { rette wrapping }\end{array}$ & 33 & 04 & 04 & 01 & 20 & 25 & 26 \\
\hline \multirow{3}{*}{$\begin{array}{l}\mathrm{MgO} \\
\mathrm{ZnO}\end{array}$} & $\begin{array}{l}\text { Deposit of fumes from } \\
\text { burning } \mathrm{Mg} \text { ribbon }\end{array}$ & 88 & 86 & 04 & 02 & 90 & 93 & 87 \\
\hline & Deposit of fumes from & & & & & & & \\
\hline & $\mathrm{Zn}$ arc & 99 & 80 & 15 & 05 & 93 & 79 & 80 \\
\hline
\end{tabular}

${ }^{8}$ H. Rubens and H. von Wartenberg, Verh. d. D. Phys. Ges. 13, 796 (1911).

${ }^{9}$ W. W. Coblentz, Investigations of infrared spectra, part I pp. 180 and 182. 
Other possibilities for windows in this region are mica, quartz, glass and cellophane. Their transmissions are given in Table III.

In a $\mathrm{MgO}$ deposit, we have an interesting absorption at $22.9 \mu$. It seemed from the results given in Table III that one might expect a reststrahlen for $\mathrm{MgO}$ near $23 \mu$. The Vitrofrax Corporation of Los Angeles supplied the author with some beautiful synthetic crystals of $\beta$ - MgO with which experiments were made. There is no doubt but that this material showed a strong reststrahlen near $23 \mu$ as will be observed from its reflectivity given in Table IV.

TABle IV. Percent reflection

\begin{tabular}{|c|c|c|}
\hline Description of reflector & $22.9 \mu$ & $32.8 \mu$ \\
\hline Deposit of $\mathrm{MgO}$ from burning $\mathrm{Mg}$ ribbon & 0 & 0 \\
\hline Reflection $\beta-\mathrm{MgO}$ & 80 & 33 \\
\hline Galena & 28 & 24 \\
\hline Stibinite & $>16$ & - \\
\hline Mica & 32 & - \\
\hline Paraffin & 04 & - \\
\hline Pencil mark on paper & 09 & - \\
\hline Soot coating & 43 & 48 \\
\hline \multirow{3}{*}{ Silver covered with $\left\{\begin{array}{l}\mathrm{MgO} \text { coating } \\
\mathrm{ZnO} \text { coating } \\
\text { Optical black }\end{array}\right.$} & 08 & 91 \\
\hline & 01 & 52 \\
\hline & 31 & - \\
\hline Gold foil blackened with bismuth & $>19$ & - \\
\hline $\mathrm{KBr}$ & 04.3 & - \\
\hline & 05.5 & - \\
\hline $\mathrm{KBr}+1.5 \mu \mathrm{CaF}_{2}$ deposited by evaporation & 10 & - \\
\hline $\mathrm{KI}+1.5 \mu \mathrm{CaF}_{2}$ deposited by evaporation & 13 & - \\
\hline
\end{tabular}

It was not convenient to measure the reflectivity of $\beta-\mathrm{MgO}$ for the other wave-lengths but it was possible to substitute the magnesia for one of the reststrahlen plates and determine the relative galvanometer deflections. This gives the ratio of the reflectivity of $\mathrm{MgO}$ to that of the reststrahlen plate. Assuming 0.7 for the reflectivity of the reststrahlen plates we get the approximate values for the reflectivity which are given in Table $\mathrm{V}$.

TABLE V. Percent reflection of $\beta=M g O$.

\begin{tabular}{lllllll}
\hline \hline $6.7 \mu$ & $8.7 \mu$ & $20.75 \mu$ & $22.9 \mu$ & $27.3 \mu$ & $29.4 \mu$ & $32.8 \mu$ \\
\hline 5 & 10 & 49 & 80 & 42 & 35 & 33 \\
\hline \hline
\end{tabular}

S. Tolksdor ${ }^{10}$ reported the fundamental for $\mathrm{MgO}$ at $14.2 \mu$ but since $\mathrm{MgO}$ has a cubic lattice and therefore only one reststrahlen, it does not seem possible that the $14.2 \mu$ absorption that he reports can be the fundamental. This point requires further investigation.

S. Tolksdorf predicts, from the absorption spectrum of $\mathrm{ZnO}$, that this material has fundamental absorption bands at 22 and $28 \mu$. The data in Table III give an absorption for one and not the other of these bands. An investigation of the reflectivity of zincite is being made to clear up these points.

Measurements on a KI crystal would indicate that a layer of this material $2 \mathrm{~cm}$ in thickness would transmit 50 percent of the $32.8 \mu$ reststrahlen.

${ }^{10} \mathrm{~S}$. Tolksdorf, Zeits. f. phys. Chem. 132, 161 (1928). 